\title{
Sunshine-based Global Solar Radiation Modelling: Case Study of Putrajaya, Malaysia
}

\author{
Kheng Yew Tsung, Yun Ii Go* \\ School of Engineering and Physical Sciences, Heriot-Watt University Malaysia. No 1, Jalan Venna P5/2, Precinct \\ 5, 62200 Putrajaya \\ *Corresponding author: y.go@hw.ac.uk
}

\begin{abstract}
Article History
Received: March 18, 2020

Received in revised form: May 18, 2020

Accepted: June 01, 2020

Published Online: June 30, 2020
\end{abstract}

\begin{abstract}
Electricity demands are on the rise and with it, carbon dioxide emissions from many conventional power plants are increasing. In the efforts to mitigate such phenomena, the Malaysian government seeks to implement Building Integrated Photovoltaic (BIPV) projects. Early stage studies on Global Solar Radiation (GSR) have been carried out in several sta tes in Malaysia including Penang, Kuala Lumpur and Kota Bharu. Afterward, data from the Malaysia Meteorological Department and the Malaysia National University have been used to estimate the monthly a verage daily global radiation in various locations in Malaysia. Putrajaya, a location which is implementing Malaysian Building Integrated Photovoltaic (MBIPV) is among the locations where a GSR study is currently absent. Conventional methods ex ist for GSR estimation with the aid of pyranometer. However, this method of GSR estimation is time consuming and not cost-effective practice. The main objective of this study is to estimate the GSR in Putrajaya. This is a chieved in this study by utilizing sunshine-based data with calculated monthly average daily ex traterrestrial ra diation on a horizontal surface and monthly average maximum possible daily sunshine to plot a linearly fitted graph. Coefficients in the Angstrom-Prescott (A-P) model was generated from the plotted graph and was used for GSR estimation where $a=0.5$ and $b=0.11$. The mean percentage error (MPE) of the GSR estimation was found to be 3.4. Therefore, the estimation of GSR in Putrajaya have been successful for the first-time using sunshine-based data from dual locations method. The GSR estimation of Putrajaya in this study could benefit stakeholders in civil development sectors, policy and energy authorities.
\end{abstract}

Keywords: Angstrom-Prescott model; global solar ra diation; Putrajaya

\subsection{INTRODUCTION}

Malaysia is a tropical country placed within the South East Asia region geographically and in terms of energy supply, it is hea vily reliant on fossil fuel. $93 \%$ of its energy comes primarily from three major fossil fuel products which are coal, natural gas and crude oil and petroleum products and others. This leads to its power generation being heavily reliant on fossil fuel products like natural gas, fuel oil, coal and diesel. These products largely made up $92 \%$ of the fuel mix used in generating electricity in 2012 [1]. This heavy dependency on fossil fuel has caused the electricity cost to increase. Due to low supply of natural gas, the electricity tariff was increased by $7 \%$ in 2011 and 2014 [2]. Hence, it is facing the problem of rising cost in electricity which could have a negative impact on the economic development of the country. On top of rising electricity cost, the long-term increase in economic growth of Malaysia has caused increase in energy consumption and carbon dioxide $\left(\mathrm{CO}_{2}\right)$ emissions. In the published research paper, Ang 2008 examined the relation ship between output, pollutant emission and energy consumption, specifically, in Malaysia during the timeframe of 1971 to 1991 [3]. Malaysia was chosen as a ca se study because it was identified as one of the highest growth economies in the developing world. In addition to that, it had also ex perienced a significant increa se in pollutant emissions and energy consumption. Ang 2008 concluded that $\mathrm{CO}_{2}$ emissions and energy consumption were positively related to output in the long term. The results supported the argument that economic growth exerted 
a positive causal influencetowards the growth of energy consumption in the short and long term [3]. This leads to more energy problems in terms of increasing electricity demand to continue its economic development and the need to mitigate $\mathrm{CO}_{2}$ emissions.

The Malaysian government recognizes that the a vailable energy resource is insufficient to a ssure supply beyond 2030 . In addition to that, the forecast that electricity generation from oil would no longer be fea sible due to dwindling national oil resources. Consequently, Malaysia is likely to become a net oil importer by 2030. The study from Oh et al. 2010 considered renewable energy to be the safest and cleanest of prospective energy sources in the long term [4]. Hence, the Malaysian government is interested to develop solar energy a sone of the major sources of energy in the country. According to Mekhilef et al. 2012, the prospects of solar energy in Ma laysia appears positive and a large provision has been dedicated to implement solar PV systems in the $9^{\text {th }}$ Malaysia Pla $[5]$. As there is end orsement by policymakers and local government, this has led to attempts in implementing solar PV systems which include two Malaysian Building Integrated Photovoltaic (MBIPV) projects in Putrajaya. The first project is with bungalow hou ses in Precinct 16 and the second is with the Putrajaya Perdana Headquarters building [5]. For the government to further invest in the development of solar PV sy stems in Putrajaya, research on global solar ra diation (GSR) at the location is crucial. Hence, this study aims to estimate the GSR in Putrajaya for the benefit of the va rious sta keholders who are interested in the development of solar PV systemsin Putrajaya, like the government, local energy industry and the public.

In this paper, we intend to communicate the following: a brief literature review concerning GSR research, GSR models and the A-P model within the context of our research; a detailed account of the methodology; a nd results pertaining to achieving the estimate for GSR in Putrajaya. Alongside this, a different methodology is introduced which uses a dual location method and, ultimately, estimates of GSR will be obtained for a new location, i.e. Putrajaya, in Ma laysia. There were studies related to the estimation of the GSR in Penang, Kuala Lumpur and Kota Bharu in 1981 [6]. Later, in 1992, data from the Malaysian Meteorological Department (MET) and the Malaysian National University were used to estimate the monthly a verage daily global radiation in a greater number of locations within Malaysia. These locations included Kuala Lumpur, Petaling Jaya, Bandar Baru Bangi, Kota Baru, Senai, Bayan Lepas, Kuching and Kota Kinabalu [7]. Currently, the GSR in Putrajaya, a location identified for implementing solar PV systems, has yet to be estimated. Thus, there is a need to estimate GSR in Putrajaya to maximize the potential use of solar PV systems there.

The ideal method to obtain the amount of GSR at a location is to install a measuring device like a pyranometer at the site to observe and document its day-to-day recordings. However, this can be a time-consuming a nd costly practice. Hence, models a re commonly used to estimate GSR to avoid this. These models a re usually based on astronomical factors like hour angle, solar declination, the solar constant and sun to earth distance; geographical fa ctors like longitude, latitude and elevation; geome trical factors like azimuth angle, surface tilt angle, sun azimuth angle and sun elevation angle; physical factors like water vapor content, scattering of air molecules and scattering of dust and other elements in the atmosphere like $\mathrm{O}_{2}, \mathrm{CO}_{2}$, $\mathrm{N}_{2}$, etc.; and meteorological factors like extraterrestrial solar radiation, temperature, sunshine duration, precipitation, effects of cloudiness, relative humidity, evaporation, soil temperature, etc. [8].

\subsection{METHODOLOGY}

There are numerous models u sed to predict GSR based on the meteorological parameters. The models were categorized base on sunshine, cloud, temperature and other meteorological parameters, as shown in Ta ble 1 [8]. Additionally, the global solar energy models were grouped by modelling techniques such as linear, nonlinear, artificial intelligence and fuzzy logic modelling techniques in a review. The reviewers discovered the models used to estimate GSR in published works were mostly correlated to sunshine duration, air temperature, rela tive humidity and geographical parameters like la titude, longitude and altitude [9].

Table 1 Models based on meteorological parameters found in [8].

\begin{tabular}{|l|c|}
\hline Models & Quantity \\
\hline Sunshine-based & 35 \\
\hline Cloud-based & 6 \\
\hline Temperature-based & 16 \\
\hline Other meteorological parameter-based & 21 \\
\hline
\end{tabular}

Various studies on global solar ra diation had been carried out at different locations in the world. Table 2 presents sunshine based model regression equation cla ssifications. For Malaysia context, several models were proposed and used to estimate monthly a verage global sola r ra diation in selective areas including Penang, Kuala Lumpur, Kota Bharu at the earlier sta ge and followed by Petaling Ja ya, Bandar Baru Bangi, Kota Baru, Senai, Ba yan Lepas, Kuching and Kota Kina balu excluded Putrajaya. Thus, 
this paper presents the global solar ra diation at Putrajaya using sunshine based empirical models. The conventional a pproach to mea sure global solar radiation at a specific location relies on pyranometer or manual recording method on daily basis. These methods required high precision of measuring devices, big da ta storage capabilities which are time-consuming and costly. The contribution of this paper is to exhibit a reference of global solar radiation at Putrajaya for a braid range of beneficiarie s including energy policy maker, local authority, urban planner and energy investor etc.

Table 2 Sunshine based model regression equation classifications [10]-[16].

\begin{tabular}{|c|c|}
\hline \multicolumn{2}{|c|}{ Regression Equation } \\
\hline Linear & Quadratic \\
\hline $\begin{array}{c}\frac{H}{H_{O}}=\mathrm{a}+\mathrm{b} \log \left(\frac{n}{N}\right) \\
\frac{H_{g}}{H_{g}}=0.29+0.52(\mathrm{~S})\end{array}$ & $\frac{H_{g}}{H_{o}}=0.145+0.845(S)-0.280(\mathrm{~S})^{2}$ \\
\hline $\begin{array}{l}\frac{H_{O}}{H_{g}}=0.32+0.42(\mathrm{~S}) \\
\frac{H_{g}}{H_{g}}=0.29 \operatorname{CoS} \varphi+0.52(\mathrm{~S}) \\
\frac{H_{g}}{H_{g}}=0.18+0.62(\mathrm{~S})\end{array}$ & $\begin{array}{c}\text { Cubic } \\
\frac{H_{g}}{H_{o}}=a+b\left(\frac{s}{s_{o}}\right)+\mathrm{c}\left(\frac{s}{s_{o}}\right)^{2}+\mathrm{d}\left(\frac{s}{s_{o}}\right)^{3}\end{array}$ \\
\hline
\end{tabular}

In comparison to other models, the Angstrom-Prescott (A-P) model is most widely used to estimate GSR at a location. This is mainly because, firstly, there is readily a vailable meteorological da ta for the sunshine-based model. That means that MET can provide solar ra diation data like the daily hourly GSR and the average daily sunshine duration to be used for computation in the A-P model. Secondly, the linear models derived from the A-P model a re ra nked high in global performance indicator (GPI). A review and statistical analysis were conducted on the various models used to predict GSR found that the linear models performed better than other models. The review categorized the various types of GSR models as linear, polynomial, logarithmic, exponential, power and hybrids. Using ten statistical indicators, they introduced a global performance indicator (GPI) to rank the performance of the different models. Out of 101 models, their results showed that the linear model took first a nd third place while the poly nomial model took second place. Within the top ten, 6 were linear models [17]. Thirdly, the A-P model is prefered due to its simplicity a s linear model and its reliability as a tool to estimate the GSR for practical applications like solar PV sy stem s [18]. Monthly average daily extraterrestrial ra diation, $H_{0}$ and average maximum possible daily sunshine duration within a month, $S_{0}$ can be calculated using equation (1) and (2) as shown below.

$$
\begin{gathered}
H_{0}=\frac{24 \times 3600}{\pi} I_{s c}\left[1+0.033 \cos \left(\frac{360 n}{365}\right)\right]\left[\cos \varphi \cos \delta \sin \omega_{s}+\frac{\pi}{180} \omega_{s} \sin \varphi \sin \delta\right] . \\
S_{0}=\frac{2}{15} \omega_{s} .
\end{gathered}
$$

In equation (1) and (2), $I_{s c}$ is the solar constant with a value of $1367 \mathrm{~W} \mathrm{~m}^{-2}, n$ is the number of day in the year beginning at first of January, $\varphi$ is the la titu de of the location measured in ${ }^{\circ}, \delta$ is the solar declination measured in degree and $\omega_{s}$ is the sunset hour angle measure in degree. Furthermore, both, $\delta$ and $\omega_{s}$, from equation(1) can be calculated using equations (3) a nd (4) as shown below.

$$
\begin{gathered}
\delta=23.45 \sin \left(\frac{360}{365}[284+n]\right) . \\
\omega_{s}=\cos ^{-1}(-\tan \varphi \tan \delta) .
\end{gathered}
$$

First, determining the average daily global ra diation on a horizontal surface within a month $(H)$. The first step wa s to compute the average daily GSR data from the hourly GSR data provided by MET. This was done in two stages; the first stage was to compute the daily GSR from the hourly GSR and the second stage wa s to compute the average daily GSR in a month from the daily GSR. In the first stage, the daily GSR data wa scomputed by summing the hourly GSR for a given day as shown in equation (5) below.

$$
H_{\text {daily }}=\sum_{i=1}^{i=d} H_{i, h}
$$


Here, $H_{\text {daily }}$ is the daily GSR, $H_{i, h}$ is the hourly GSR and $d$ is the number of hours with solar radiation in a day. In the second sta ge, the a verage daily global ra diation in a month was obtained by using equation (6).

$$
H=\frac{1}{m} \sum_{i=1}^{i=m} H_{\text {daily }_{i}}
$$

Whereby, $H$ is the daily a verage GSR in a month, $H_{\text {daily }_{i}}$ is the daily GSR and $m$ is the number of days in a month. The daily a verage wa s computed for each month in a year from Ja nuary to December and used in the A-P model for the linear regression [19]. In this study, the average daily values in a month was chosen to be used for computation instead of the daily values because of 4 main reasons. Firstly, the model wa s originally intended to be used with the monthly a verage daily data [20]. Secondly and more importantly, a study conducted in 2009 to compare the different timescales on the A-P model and found that although there were large effects on the coefficients, a and b, there were no significant impact on the estimation a ccuracy of the GSR [21]. This was due to the little change in $(a+b)$ values for the different timescales. Thirdly, in the same study, it wa s a lso mentioned that the sunshine-based methods, particularly the A-P model performed the best generally. Finally, from a pragmatic point of view, there would be less computation required in using the a verage daily values in a month compared to the daily va lues. This was supported by a review article on solar ra diation models as it was concluded that the linear, termed as first-order Angstrom type, correlation surpasses the second and third order, both, in the accuracy of the estimated values of the average daily global ra diation on a horizontal surface in a month and in requiring less computational work [22].

Second, determining the a verage daily bright sunshine duration within a month (S). Since the daily sunshine duration data obta ined from MET came with the a verage daily sunshine duration for a given month, no computation was required.

Third, determining the monthly average daily extraterrestrial ra diation on a horizontal surface $\left(H_{0}\right)$. The monthly a verage daily extraterrestrial ra diation on a horizontal surface was computed using equation(1). Due to the complex appearance of equation (1), it was simplified into equation(7) for ea se of computation.

$$
H_{0}=A \times B \times(C+D) .
$$

In equation (7), $A=\frac{24 \times 3600}{\pi} I_{s c}, B=1+0.033 \cos \left(\frac{360 n}{365}\right), C=\cos \varphi \cos \delta \sin \omega_{s}$ and $D=\frac{\pi}{180} \omega_{s} \sin \varphi \sin \delta$. In addition to that, recommended values of $n$ that were used in the computation. These values were corresponding to the following dates: $17^{\text {th }}$ of January, $16^{\text {th }}$ of February, $16^{\text {th }}$ of March, $15^{\text {th }}$ of April, $15^{\text {th }}$ of May, $11^{\text {th }}$ of June, $17^{\text {th }}$ of July, $16^{\text {th }}$ of August, $15^{\text {th }}$ of September, $15^{\text {th }}$ of October, $14^{\text {th }}$ of November and $10^{\text {th }}$ of December [17]. Table 3 shows these dates and their corresponding $n$ values.

Table 3 Recommended values of $n$ used in computation and their corresponding dates.

\begin{tabular}{l|c|c}
\hline \multicolumn{1}{c|}{ Month } & Date & n \\
\hline January & 17 & 17 \\
\hline February & 16 & 47 \\
\hline March & 16 & 75 \\
\hline April & 15 & 105 \\
\hline May & 15 & 135 \\
\hline June & 11 & 162 \\
\hline July & 17 & 198 \\
\hline August & 16 & 228 \\
\hline September & 15 & 258 \\
\hline October & 16 & 288 \\
\hline November & 14 & 318 \\
\hline December & 10 & 344 \\
\hline
\end{tabular}

Fourth, determining the monthly a verage maximum possible daily sunshine $\left(S_{0}\right)$. The computation was done according to equation(2).

Fifth, determining the coefficients in the linear A-P Model. To a chieve this, a scatter plot diagram of the ra tio $\frac{H}{H_{0}}$ against the ratio $\frac{S}{S_{0}}$ wa s created. The va lues of $\frac{H}{H_{0}}$ and $\frac{S}{S_{0}}$ covered the duration of 2011 to 2014 . Subsequently, the scatter plot was linearly fitted and the linear equation was obtained. The coefficients $a$ and $b$ in the linear A-P model were observed from the linear equation.

Sixth, validating the model using MBE, MAE, RMSE and MPE according to equations (8), (9), (10) and (11) through 
computation.

$$
\begin{gathered}
R M S E=\sqrt[2]{\frac{1}{n} \sum_{i=1}^{i=n}\left(\bar{H}_{i, m}-\bar{H}_{i, c}\right)^{2} .} \\
M B E=\frac{1}{n} \sum_{i=1}^{i=n}\left(\bar{H}_{i, m}-\bar{H}_{i, c}\right) . \\
M A E=\frac{1}{n} \sum_{i=1}^{i=n}\left|\bar{H}_{i, m}-\bar{H}_{i, c}\right| . \\
M P E=\frac{100}{n} \sum_{i=1}^{i=n}\left(\frac{\bar{H}_{i, m}-\bar{H}_{i, c}}{\bar{H}_{i, m}}\right) .
\end{gathered}
$$

In equations (8), (9), (10) and (11), $\bar{H}_{i, m}$ and $\bar{H}_{i, c}$ are the measured and estimated monthly a verage daily GSR respectively and $n$ is the number of observations. The computation was done with data of the measured monthly average daily GSR data and the estim a ted monthly a verage daily GSR a KLIA (la titude $2.7333^{\circ}$ ) since there were no available measured GSR data at Putrajaya. The estimated monthly a verage daily GSR at KLIA wa s computed according to equation(12) u sing the la titude of KLIA. Here, equation (12) is the rearranged form of equation (1).

$$
H=\left(H_{0}\right)\left[a+b\left(\frac{s}{s_{0}}\right)\right] .
$$

\begin{tabular}{|c|c|c|}
\hline $\begin{array}{l}\text { Stage } 5 \\
\text { Determining the } \\
\text { coefficients in the } \\
\text { linear A-P Model. }\end{array}$ & $\begin{array}{l}\text { Stage } 4 \\
\text { Determining the } \\
\text { monthly average } \\
\text { maximum possible } \\
\text { daily sunshine. }\end{array}$ & $\begin{array}{l}\text { Stage } 3 \\
\text { Determining the } \\
\text { monthly average daily } \\
\text { extraterrestrial } \\
\text { radiation. }\end{array}$ \\
\hline Stage 6 & Stage 7 & Stage 8 \\
\hline $\begin{array}{l}\text { Validating the model's } \\
\text { accuracy. }\end{array}$ & $\begin{array}{l}\text { Estimating the monthly } \\
\text { average daily GSR. }\end{array}$ & $\begin{array}{l}\text { Compare with adjacent city } \\
\text { and other cities in the world. }\end{array}$ \\
\hline
\end{tabular}

Seventh, and finally, estimating the monthly a verage daily GSR on a horizontal surface in Putra jaya (latitude $2.9264^{\circ}$ ). To do this, computation was done a ccording to equation (12) using the latitude of Putrajaya. Figure 1 indicates the overall workflow and the main functionalblocks involved in each methodological sta ge.

Stage 1
Determining the
average daily global
radiation.

Figure 1 Overall workflow and its functional block at each stage.

\subsection{RESULTS ANDDISCUSSION}

This section will cover the results of monthly a verage daily extraterrestrial radiation and a verage maximum possible daily sunshine duration within a month. The data from MET and computational values will be compared. This is followed by the results of linear fitting plot. Comparison with selected countries in various geographical locations in the world will be presented. Finally, the results of the estimated and measured GSR will be demonstrated. 


\subsection{Results of $\mathrm{S}_{0}$ and $\mathrm{H}_{0}$}

The results from Table 4 were attained through computation based on the latitude of KLIA $\left(2.7333^{\circ}\right)$ and MARDI $\left(2.9833^{\circ}\right)$, values of $n, \delta, \omega, S_{0}$ and $H_{0}$ in accordance to equations (1), (2), (3) and (4). The $S_{0}$ and $H_{0}$ results from Table 4 is further used to compute the data required for the A-P model.

Table 4 Results of computed monthly data of $\delta, \omega_{s}, \mathrm{~S}_{0}$ and $\mathrm{H}_{0}$.

\begin{tabular}{|c|c|c|c|c|c|}
\hline Month & $\mathbf{n}$ & $\boldsymbol{\delta}\left({ }^{\circ}\right)$ & $\omega_{s}\left({ }^{\circ}\right)$ & $\mathbf{S}_{\mathbf{0}}(\mathbf{h})$ & $\mathbf{H}_{0}\left(\mathrm{MJ} / \mathrm{m}^{2}\right.$ day $)$ \\
\hline January & 17 & -20.92 & 88.86 & 11.85 & 35.15 \\
\hline February & 47 & -12.95 & 89.31 & 11.91 & 36.79 \\
\hline March & 75 & -2.42 & 89.87 & 11.98 & 37.74 \\
\hline April & 105 & 9.41 & 90.50 & 12.07 & 37.22 \\
\hline May & 135 & 18.79 & 91.02 & 12.14 & 35.64 \\
\hline June & 162 & 23.09 & 91.27 & 12.17 & 34.55 \\
\hline July & 198 & 21.18 & 91.16 & 12.15 & 34.89 \\
\hline August & 228 & 13.45 & 90.71 & 12.10 & 36.31 \\
\hline September & 258 & 2.22 & 90.12 & 12.02 & 37.30 \\
\hline October & 288 & -9.60 & 89.49 & 11.93 & 36.85 \\
\hline November & 318 & -18.9 & 88.98 & 11.86 & 35.41 \\
\hline December & 344 & -23.05 & 88.73 & 11.83 & 34.49 \\
\hline
\end{tabular}

\subsection{Results of $\frac{H}{H_{0}}$ and $\frac{S}{S_{0}}$}

The data of $H$ and $S$ from MET and $S_{0}$ and $H_{0}$ from Table 3 was used to compute the ratios of $\frac{H}{H_{0}}$ and $\frac{S}{S_{0}}$ are shown in Table 4. The results in Table 5 shows both computable data of $\frac{H}{H_{0}}$ and $\frac{S}{S_{0}}$. All data of $\frac{H}{H_{0}}$ and $\frac{S}{S_{0}}$ were computable for the months of September, October and November. All data of $\frac{H}{H_{0}}$ and $\frac{S}{S_{0}}$ were incomputable for the month of December. Some data of $\frac{H}{H_{0}}$ and $\frac{s}{s_{0}}$ were computable for Ja nuary, February, March, April, May, June, July and August.

Table 5 Results of computed $\frac{H}{H_{0}}$ and $\frac{S}{S_{0}}$

\begin{tabular}{|c|c|c|c|c|c|c|c|c|}
\hline \multirow{2}{*}{ Month } & \multicolumn{4}{|c|}{$H / H_{0}$} & \multicolumn{4}{|c|}{$S / S_{0}$} \\
\hline & Set 1 & Set 2 & Set 3 & Set 4 & Set 1 & Set 2 & Set 3 & Set 4 \\
\hline January & - & - & - & - & - & - & - & - \\
\hline February & - & 0.4840 & 0.4733 & - & - & 0.5363 & 0.3063 & - \\
\hline March & - & 0.4649 & 0.6288 & - & - & 0.3722 & 0.5644 & - \\
\hline April & - & 0.5989 & - & - & - & 0.5468 & - & - \\
\hline May & - & 0.5787 & 0.6117 & - & - & 0.5382 & 0.5561 & - \\
\hline June & - & 0.6124 & 0.6162 & - & - & 0.5212 & 0.5351 & - \\
\hline July & - & 0.5994 & 0.5691 & - & - & 0.4504 & 0.4579 & - \\
\hline August & - & 0.5779 & 0.5871 & - & - & 0.3832 & 0.4507 & - \\
\hline September & 0.4815 & 0.5803 & 0.5530 & 0.5615 & 0.4874 & 0.4608 & 0.4299 & 0.03360 \\
\hline October & 0.4380 & 0.5580 & 0.6074 & 0.5463 & 0.4252 & 0.4650 & 0.4405 & 0.03431 \\
\hline
\end{tabular}




\begin{tabular}{|c|c|c|c|c|c|c|c|c|}
\hline November & 0.4278 & 0.4917 & 0.5552 & 0.5167 & 0.3456 & 0.4111 & 0.3523 & 0.03290 \\
\hline December & - & - & - & - & - & - & - & - \\
\hline
\end{tabular}

\subsection{Results of Linear Fitting of $\frac{H}{H_{0}}$ against $\frac{S}{S_{0}}$ Plot}

The result of the linear fitting of the scatter diagramis given by equation (13).

$$
\frac{H}{H_{0}}=0.5+0.11\left(\frac{S}{S_{0}}\right) \text {. }
$$

Equation (13) reveals that $a=0.5, b=0.11$ and $a+b=0.61$. Further analysis was performed by comparing between the results of $a, b$ and $a+b$ from this study with that of Sopian et al. 1992 in their respective locations of Putrajaya and Kuala Lumpur as shown in Table 6 [7].

Table 6 Results of $a, b$ and $a+b$ from Putrajaya and Kuala Lumpur [7].

\begin{tabular}{|l|c|c|c|}
\hline Location & $\boldsymbol{a}$ & $\boldsymbol{b}$ & $\boldsymbol{a}+\boldsymbol{b}$ \\
\hline Putrajaya & 0.5 & 0.11 & 0.61 \\
\hline Kuala Lumpur & 0.27 & 0.35 & 0.62 \\
\hline
\end{tabular}

Table 6 shows that there is variation in the values of $a$ and $b$ for geographical locations of Putrajaya and Kuala Lumpur. However, the value of $a+b$ is approximately the same. Table 7 presents a comparison with selected countries in various geographical locations in the world using with different regression equations and coefficients.

Table 7 Comparison with selected countries in various geographical locations in the world [23]-[26].

\begin{tabular}{|l|l|c|c|}
\hline \multicolumn{1}{|c|}{ Country } & \multicolumn{1}{|c|}{ Region } & Regression Equation & Reference \\
\hline Turkey & Middle East & $\frac{H}{H_{o}}=0.2786+0.4160\left(\frac{S}{S_{o}}\right)$ & {$[23]$} \\
\hline India & South Asia & $\frac{H}{H_{o}}=0.34+0.32\left(\frac{S}{S_{o}}\right)$ & {$[24]$} \\
\hline Zambia & East Africa & $\frac{H}{H_{o}}=0.240+0.513\left(\frac{S}{S_{o}}\right)$ & {$[25]$} \\
\hline Oman & Middle East & $\left.\frac{H}{H_{o}}=0.9428-1.2027\left(\frac{S}{S_{o}}\right)+0.9336\left(\frac{S}{S_{o}}\right)\right)^{2}$ & {$[26]$} \\
\hline $\begin{array}{l}\text { Malaysia } \\
\text { (Putrajaya) }\end{array}$ & Southeast Asia & $\frac{H}{H_{o}}=0.5+0.11\left(\frac{S}{S_{o}}\right)$ & - \\
\hline
\end{tabular}

\subsection{Results of Estimated and Measured GSR}

The coefficients $a$ and $b$ obtained through linear fitting is used to estimate the GSR using the la titude of Putrajaya and equation (12). Both estimated and measured GSR results were compared using a linked plot diagram as shown in Figure 2. 


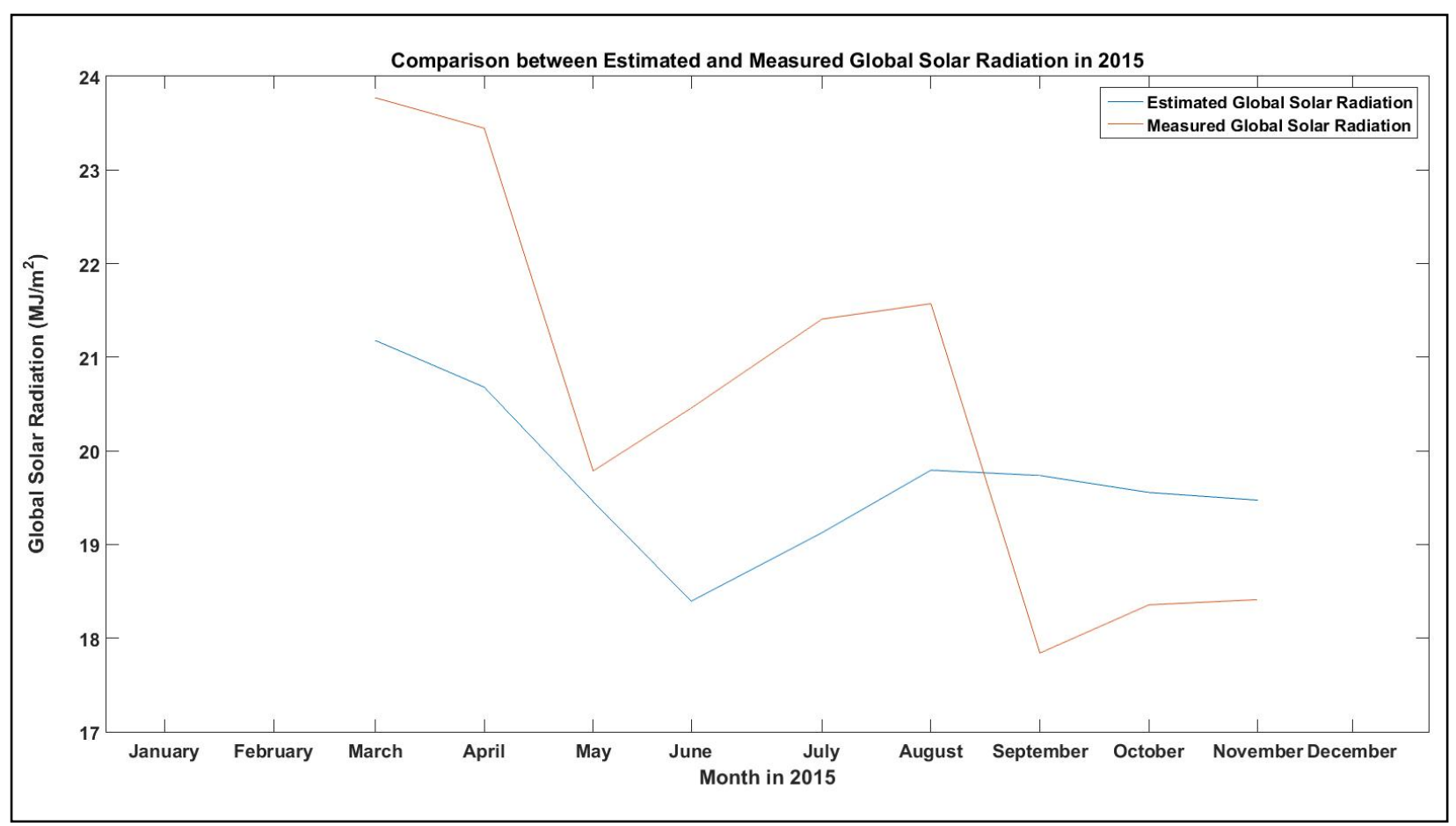

Figure 2 Results of the linked plot diagram of estimated and measured monthly a verage daily GSR.

The linked plot diagram from Figure 2 shows that out of 12 months, this study was able to estimate the monthly average daily GSR for 9 months while not being able to estimate the monthly a verage daily GSR for 3 months which was January, February and December. Figure 2 also shows that out of the 9 a vailable estimates, 6 were underestimated and 3 were overestimated. The months of March to August showed overestimation while the months of September to November showed underestimation. The results obtained and shown in Table 4 support the choice of using the sunshine-based linear A-P model in this study. They were ea sily computed due to the readily a vailable sunshine-based data and the relative simple to compute due to the linear characteristics of the A-P model as wa smentioned stated by (Paulescu, et a 1. 2016) [18]. These results can function as a reference for future researches on GSR in Putrajaya as they reusable without having to be computed again. The substantial quantity of missing data amounting to $47.9 \%$ in Table 5 is mainly due to the defective data owing to the pyranometer malfunctioning and the screening process practiced in the methodology to ensure the remaining data was reliable as discussed in [19]-[21]. This work chosen a four-year window data based on several reviews on GSR models using a vailable sunshine duration and GSR data around the world [17]. Ourstudy used four years which fell within that range. Results from Table 6 show the of the A-P coefficients obtained in this study at Putrajayain comparison to a previous study at Kuala Lumpur. The difference in the coefficients, $a$ and $b$, is not uncommon as it is usually associated with difference in loca tion [19]. More importantly, the sum of $a+b$ represents the overall a tmospheric transmittance of a cloudless sky. In the case whereby there are no cloudsin the sky, $\frac{s}{S_{0}}=1$ which makes $a+b=\frac{H}{H_{0}}$. From Table 6, the sum of $a+b$ in Putrajaya and Kuala Lumpur showed similarvalues. The absence of estimates for the months of January, February and December as evident in Figure 2 is mainly due to missing data from MET. The coefficients, $a$ and $b$, ca n be used along with sunshine-based data can be used to estimate GSR at a location with the application of equation (12).

\subsection{CONCLUSION}

This study has shown that by using data from dual nearby locations, estimates of the GSR in Putrajaya has be obtained for the first time. Coefficients in the Angstrom-Prescott (A-P) model was generated from the plotted graph and was used for GSR estimation where $a=0.5$ and $b=0.11$. The mean percentage error (MPE) of the GSR estimation was found to be 3.4 and the value of $(a+b)$ is close to the value obtained at Kuala Lumpur which is 0.61 and 0.62 respectively. Thus, the finding of this paper provides an in dication of global solar radiation at Putrajaya (hub of administration) which can be useful to the stakeholders including renewable energy policy maker, sustainable energy development a uthority, energy commission and renewable energy project investors and developers. The outcome of this work can also serve as reference model for several locations adjacent to Putrajaya via comparative studies. Ba sed on this study, suggestions for further work including estimating the global solar radiation in Putrajaya using other models and different time scales; standardizing statistical tools in evaluating results or valida ting models; investigating the effects of regional haze on global solar radiation in Putrajaya; investigating the effects of monsoon weather on global solar ra diation and setting up a pyranometer at a location in Putrajaya to collect long term global 
solar radiation data. Other recommendations for future work of the proposed work including the adoption of smart model to improve the estimation [27], consider both direct and diffuse solar radiation [28]\&[30], climatic parameters [29], adoption of genetic a lgorithm [31] and influence of environmental pollution [32].

\section{Acknowledgements}

The authors would like to acknowledge the following: Malaysian Meteorological Department (MET) for providing solar radiation data.

\section{References}

[1] Energy Commision. Malaysia Energy Statistics Handbook 2014; Suruhanjaya Tenaga (Energy Comission): Putrajaya, Malaysia (2014): 32.

[2] Enerdata, 2015. Electricity Tariffs in Malaysia - current situation and outlook. Available online: http://www.enerdata.net (accessed on 12 February 2015).

[3] Ang, J.B. 2008. Economic development, pollutant emissions and energy consumption in Malaysia. Journal of Policy Modeling: 271-278.

[4] Oh, T.H.; Pang, S.Y.;Chua, S.C. 2010. Energy policy and alternative energy in Malaysia: Issues and challenges for sustainable growth. Renewable and Sustainable Energy Reviews: 1241-1252.

[5] Mekhilef, S.; Safari, A.; Mustaffa, W.E.S.; Saidur, R.; Omar, R.; Younis, M.A.A. 2012. Solar energy in Malaysia: Current state and prospects. Renewable and Sustainable Energy Reviews. 16: 386- 396.

[6] Chuah, D.G.; S. Lee, 1981. S. SOLAR RADIATION ESTIMATES IN MALAYSIA. Solar Energy. 26: 33-40.

[7] Sopian, K.; Othman, M.Y.H. 1992. Estimates of monthly average daily global solar radiation in Malaysia. Renewable Energy. 2(3): 319-325.

[8] Besharat, F.; Dehghan, A.A.; Faghih, A.R. 2013. Empirical models for estimating global solar radiation: A review. Renewable and Sustainable Energy Reviews. 21: 798-821.

[9] Teke, A.; Yıldırım, H.; Çelik, O. 2015. Evaluation and performance comparison of different models for the estimation of solar radiation. Renewable and Sustainable Energy Reviews. 50: 1097-1107.

[10] Yew, T.K. 2016. Estimation of global solar radiation in Putrajaya. Master's degree project report. Heriot-Watt University, Putrajaya, Malaysia.

[11] A.Q. Jakhrani, A.K. Othman, A.R.H. Rigit and S.R. Samo. 2011. Model for Estimation of Global Solar Radiation in Sarawak, Malaysia. World Applied Sciences Journal 14 (Special Issue of Food and Environment). 83-90.

[12] Wan Nik, W., Ibrahim, M., Samo, K. and Muzathik, A. 2012. Monthly mean hourly global solar radiation estimation. Solar Energy, 86(1): 379-387.

[13] Namrata, K., Sharma, S. and Saksena, S. 2013. Comparison of Different Models for Estimation of Global Solar Radiation in Jharkhand (India) Region. Smart Grid and Renewable Energy, 04(04): 348-352.

[14] Bakirci, K. 2009. Correlations for estimation of daily global solar radiation with hours of bright sunshine in Turkey. Energy, 34(4): 485-501.

[15] Namrata, K., Sharma, S. and Saksena, S. 2011. Comparison of Different Models for Estimation of Global Solar Radiation in Jharkhand (India) Region. International Journal of Science and Advanced Technology 2(4): 132-137.

[16] Onyango, A. and Ongoma, V. 2015. Estimation of mean monthly global solar radiation using sunshine hours for Nairobi City, Kenya. Journal of Renewable and Sustainable Energy. 7(5): 053105

[17] Despotovic, M.; Nedic, V.; Despotovic, D.; Cvetanovic, S. 2015 Review and statistical analysis of different global solar radiation sunshine models. Renewable and Sustainable Energy Reviews. 52: 1869-1880.

[18] Paulescu, M.; Stefu, N.; Calinoiu, D.; Paulescu, E.; Pop, N.; Boata, R.; Mares, O. 2016. Angstrom-Prescott equation: Physical basis, empirical models and sensitivity analysis. Renewable and Sustainable Energy Reviews. 62: 495-506.

[19] Liu, X.; Mei, X.; Li, Y.; Porter, J.R.; Wang, Q.; Zhang, Y. 2010. Choice of the Angstrom-Prescott coefficients: Are time-dependent ones better than fixed ones in modeling global solar irradiance? Energy Conversion and Management. 51: 2565-2574

[20] Manzano, A.; Martín, M.; Valero, F.; Armenta, C. 2015. A single method to estimate the daily global solar radiation from monthly data. Atmospheric Research. 166: 70-82.

[21] Liu, X.; Mei, X.; Li, Y.; Zhang, Y.; Wang, Q.; Jensen, J.R.; Porter, J.R. 2009. Calibration of the Angstrom-Prescott coefficients (a,b) under different time scales and their impacts in estimating global solar radiation in the Yellow River basin. Agricultural and Forest Meteorology. 149: 697-710. 
[22] Katiyar, A.K.; Pandey, C.K. 2013. A Review of Solar Radiation Models-Part I. Journal of Renewable Energy. 2013:. 1-11.

[23] Bakirci, K. 2009. Correlations for estimation of daily global solar radiation with hours of bright sunshine in Turkey. Energy. 34(4): 485-501.

[24] Veeran, P. and Kumar, S. 1993. Analysis of monthly average daily global radiation and monthly average sunshine duration at two tropical locations. Renewable Energy. 3(8): 935-939.

[25] Jain, S. and Jain, P. 1988. A comparison of the Angstrom-type correlations and the estimation of monthly average daily global irradiation. Solar Energy, 40(2): 93-98.

[26] Ampratwum, D. and Dorvlo, A. 1999. Estimation of solar radiation from the number of sunshine hours. Applied Energy, 63(3): 161-167.

[27] Achour, L., Bouharkat, M., Assas, O. et al. 2020. Smart model for accurate estimation of solar radiation. Front. Energy. 14: $383-399$.

[28] Xiao, M., Yu, Z. \& Cui, Y. 2020. Evaluation and estimation of daily global solar radiation from the estimated direct and diffuse solar radiation. Theoretical and Applied Climatology. 140: 983-992.

[29] Dinpashoh, Y., Jahanbakhsh-Asl, S., Rasouli, A.A. et al. 2019. Impact of climate change on potential. Theoretical and Applied Climatology. 136: 185201.

[30] Junliang F. et al. 2019. Evaluation and development of empirical models for estimating daily and monthly mean daily diffuse horizontal solar radiation for different climatic regions of China. Renewable and Sustainable Energy Reviews, 105: 168-186.

[31] Jahani, B., Mohammadi, B. 2019. A comparison between the application of empirical and ANN methods for estimation of daily global solar radiation in Iran. Theoretical and Applied Climatology. 137: 1257-1269.

[32] WanxiangY. Et al 2018. A support vector machine approach to estimate global solar radiation with the influence of fog and haze. RenewableEnergy. 128(A): 155-162. 